\title{
Hardware Performance of Optical Distribution Equipment for 12-GHz Band Satellite Broadcasting using Dual-polarization
}

\author{
By Atsushi Iwasaki, ${ }^{1)}$ Masafumi NagasaKA, ${ }^{1)}$ Yuki Korzumi, ${ }^{1)}$ Masaaki KoJImA, ${ }^{1)}$ Susumu NaKazawa, ${ }^{1)}$ \\ Shoji TANAKA, ${ }^{1)}$ and Kazuya UEDA ${ }^{2)}$ \\ 1) Science \& Technology Research Laboratories, Japan Broadcasting Corporation, Tokyo, Japan \\ 2) Association of Radio Industries and Businesses, Tokyo, Japan
}

(Received June 5th, 2017)

In 2018, practical broadcasting of $4 \mathrm{~K} / 8 \mathrm{~K}$ ultra-high-definition television will start with $12-\mathrm{GHz}$ band satellite broadcasting using right- and left-hand circular polarization in Japan. For $4 \mathrm{~K} / 8 \mathrm{~K}$ satellite broadcasting reception, the Association of Radio Industries and Businesses standardized specifications of distribution equipment for home use. Therefore, we fabricated a dual-polarization receiving antenna and optical distribution equipment in accordance with the specifications. We measured the aperture efficiency and cross-polarization discrimination of the fabricated antenna, and the respective results indicated that they were more than $74 \%$ and $26 \mathrm{~dB}$. We also confirmed that the fabricated optical distribution equipment was able to deliver 50 modulated signals with $\mathrm{C} / \mathrm{N}$ degradation of $0.1 \mathrm{~dB}$.

Key Words: Satellite Broadcasting, 12-GHz Band, Dual-polarized Antenna, Radio on Fiber, UHDTV

\section{Introduction}

In 2018, practical satellite broadcasting of $4 \mathrm{~K} / 8 \mathrm{~K}$ ultra-high-definition television (UHDTV) ${ }^{1)}$ will start in Japan with 12-GHz-band (11.7-12.75 GHz) satellite broadcasting using right- and left-hand circular polarization. The Association of Radio Industries and Businesses (ARIB) standardized specifications of distribution equipment for home use for the reception of UHDTV satellite broadcasting.

ARIB STD-B63 ${ }^{2)}$ defines the intermediate frequency (IF) of right-hand circular polarization (RHCP) and left-hand circular polarization (LHCP) to deliver signals of both polarizations on a single cable simultaneously. The IF-band of RHCP, which is currently used in Japan, is 1032.23 to $2070.25 \mathrm{MHz}$, and the IF-band of LHCP is 2224.41 to $3223.25 \mathrm{MHz}$ so as not to overlap with digital terrestrial television broadcasting or the RHCP-IF band.

Because the frequency band of LHCP-IF is higher than that of the currently used RHCP-IF, the loss in coaxial cables increases when IF signals of both polarizations are delivered. Therefore, ARIB STD-B63 also defines the specifications of optical distribution equipment. This equipment consists of a radio-over-fiber system that can deliver the IF signals with low loss.

We describe in this paper the results of evaluating a dual-polarization receiving antenna and optical distribution equipment, which were fabricated in accordance with the specifications of ARIB STD-B63.

\section{Dual-Polarization Receiving System}

Figure 1 schematically shows a dual-polarization receiving system for 12-GHz-band satellite broadcasting using RHCP and LHCP, which are transmitted by a satellite whose orbital position is 110 degrees east. The dual-polarization receiving system is composed of a dual-polarization receiving antenna and distribution equipment. This system enables simultaneous reception of UHDTV programs provided with both forms of polarization.

The receiving antenna has a dual-polarized feed horn antenna and a low noise block converter (LNB) that has two converter circuits. The LNB performs frequency conversion using different local oscillation frequencies and outputs two consecutive IF bands corresponding respectively to RHCP and LHCP. In the distribution equipment, the satellite broadcasting IF signals are combined with digital terrestrial television broadcasting signals and delivered to each room via coaxial cables or optical distribution equipment.

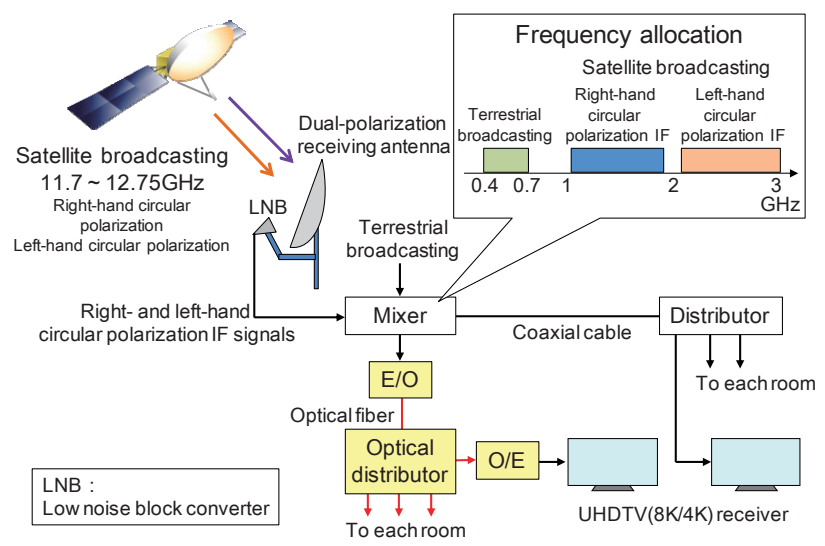

Fig. 1. Outline of dual-polarization receiving system. 


\section{Prototype Dual-Polarization Receiving Antenna}

\subsection{Requirement for dual-polarization receiving antenna}

We fabricated and tested a dual-polarization receiving antenna. The requirements for this antenna are listed in Table 1. The receiving frequency is $11.7 \mathrm{GHz}$ to $12.75 \mathrm{GHz}$, and it is possible to receive RHCP and LHCP signals simultaneously. The aperture efficiency was $70 \%$ or more, which is the same as that of the satellite broadcast receiving antenna currently used in Japan. The co-polarization and cross-polarization characteristics are in accordance with Rec. ITU-R BO.1213, ${ }^{3)}$ which is a reference pattern for 12-GHz-band receiving antennas. The required cross-polarization discrimination (XPD) is $25 \mathrm{~dB}$, which is derived from the boresight value of the reference pattern of Rec. ITU-R BO.1213.

The frequency allocation of the $12-\mathrm{GHz}$ band and the IF-band is shown in Fig. 2. ARIB STD-B63 specifies 10.678 and $9.505 \mathrm{GHz}$ as local oscillation frequencies of an LNB for RHCP and LHCP, respectively. Hence, we can convert the same radio frequency (RF) bands for both polarizations into two consecutive IF signals. The LHCP is located so as to be converted to the upper frequency band of RHCP. These local oscillation frequencies were applied to our fabricated LNB.

Table 1. Requirements for dual-polarization receiving antenna.

\begin{tabular}{|l|l|}
\hline Receiving frequency & 11.7 to $12.75 \mathrm{GHz}$ \\
\hline Receiving polarizations & $\begin{array}{l}\text { Right-hand circular polarization (RHCP) } \\
\text { and } \\
\text { Left-hand circular polarization (LHCP) }\end{array}$ \\
\hline Aperture efficiency & $70 \%$ or more \\
\hline $\begin{array}{l}\text { Main polarization and } \\
\text { cross-polarization } \\
\text { characteristics }\end{array}$ & Rec. ITU-R BO.1213 \\
\hline $\begin{array}{l}\text { Cross-polarization } \\
\text { discrimination (XPD) }\end{array}$ & $25 \mathrm{~dB}$ or more (at 0 deg.) \\
\hline $\begin{array}{l}\text { Local oscillator frequency } \\
\text { RHCP: } 10.678 \mathrm{GHz} \\
\text { LHCP: } 9.505 \mathrm{GHz}\end{array}$ \\
\hline Output frequency & $\begin{array}{l}\text { LHCP: } 1032.23 \text { to } 2070.25 \mathrm{MHz} \\
\text { Output impedance }\end{array}$ \\
\hline
\end{tabular}

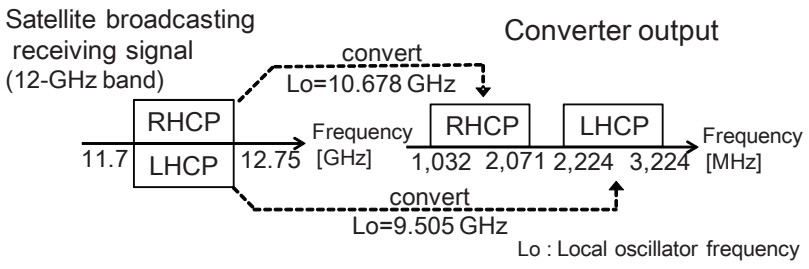

Fig. 2. Frequency relationship of converter output.

\subsection{Antenna configuration}

Figures 3 and 4 show our prototype dual-polarization receiving antenna and the antenna parameters, respectively. Offset parabolic reflector antennas with a $45-\mathrm{cm}$ diameter are popular for home use in Japan. However, for apartment buildings or in the fringe area of satellite broadcasting, antennas with an aperture diameter of $60 \mathrm{~cm}$ or larger are used. Therefore, we fabricated two reflector antennas with aperture diameters of 45 and $60 \mathrm{~cm}$. The designs of the feed antenna were the same. The ratio of the focal length to the aperture diameter (F/D) was 0.47 , and the offset angle was 58.8 degrees, which are equal to those of commercial antennas. The parabolic reflectors were fabricated using the same method as for commercial antennas. The $45-\mathrm{cm}$ reflector was made of pressed aluminum, and the $60-\mathrm{cm}$ reflector was a molded metal mesh with fiber-reinforced plastic.

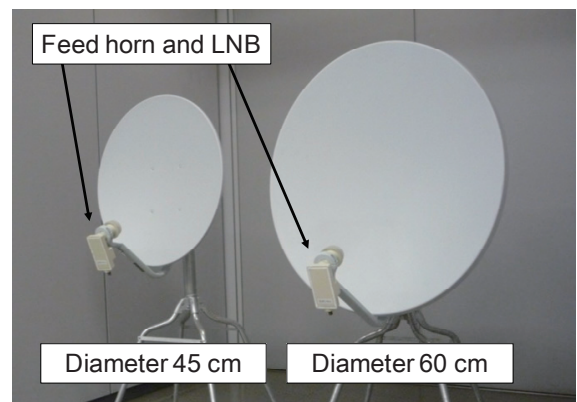

Fig. 3. Prototype dual-polarization receiving antennas.

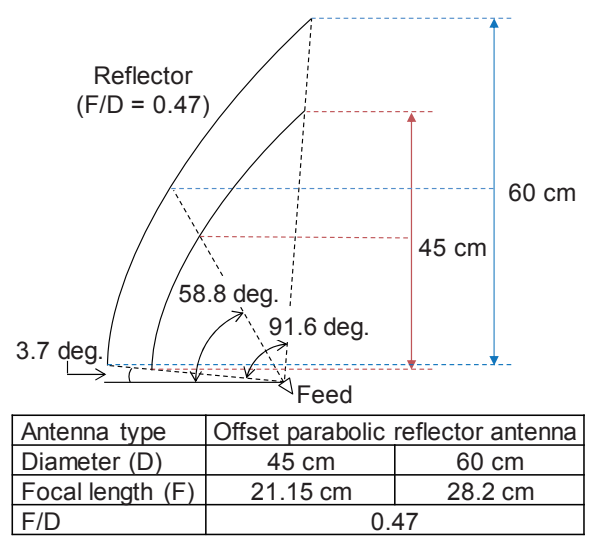

Fig 4. Parameters of prototype antenna.

\subsection{Structure of horn antenna for dual-polarization}

The prototype antenna has a horn antenna supporting dual-polarization that can separate the received signal into RHCP and LHCP. The internal structure of the dual-polarized horn antenna is illustrated in Fig. 5. The aperture of the horn is circular and is connected to a circular polarizer of the square waveguide by a tapered structure. We chose a septum type polarizer that is suitable for mass production because the septum structure does not require adjustment.
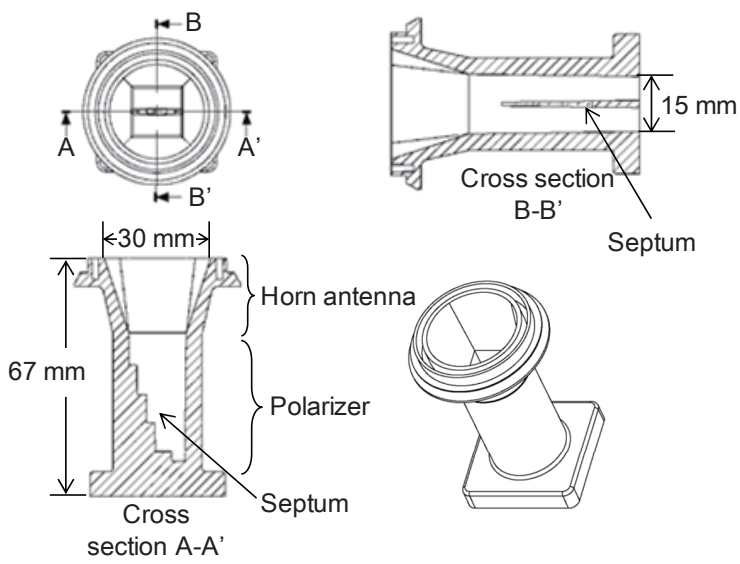

Fig. 5. Structure of dual-polarized horn antenna. 


\subsection{Converter configuration}

A block diagram of our fabricated LNB with two converter-circuits for RHCP and LHCP is shown in Fig. 6. The LNB is integrated with the feed horn antenna. The converters for RHCP and LHCP have the same configuration except for the local oscillation frequency and the mixing filter. Each LNB amplifies the 12-GHz-band input signal with a low noise amplifier and removes unnecessary waves with a band pass filter (BPF). Then, the LNB converts the 12-GHz RF band to the IF-band signal. The circuit then amplifies the IF-band signal, removes the out-of-band noise with a low pass filter or high pass filter (LPF or HPF), and mixes the signal with the other LNB's output signal.

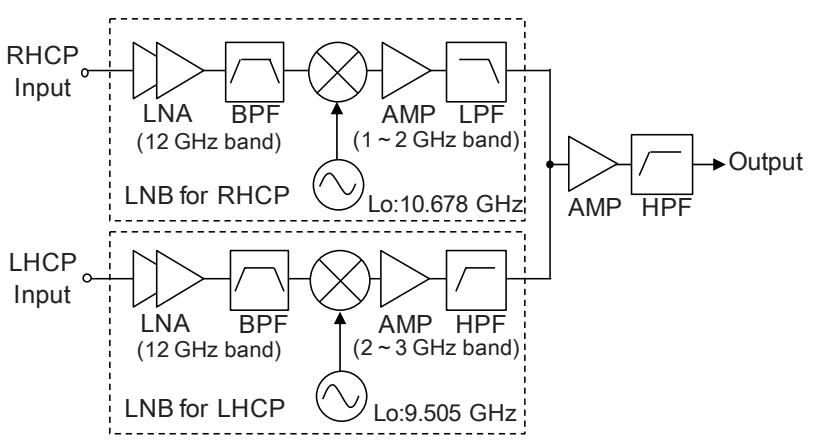

Fig. 6. Block diagram of LNB.

\section{Performance of Prototype Antenna}

\subsection{Antenna gain, cross polarization discrimination}

Tables 2 and 3 list the measured results of the antenna gain and the XPD. The measurement frequency was set according to six points described in JEITA CP-5104C. ${ }^{4)}$ The measured results showed that the gain and the XPD of the $45-\mathrm{cm}$ diameter antenna were $33.6 \mathrm{dBi}$ (aperture efficiency: 74\%) and $26 \mathrm{~dB}$, respectively. The gain and the XPD of the $60-\mathrm{cm}$ antenna were $36.1 \mathrm{dBi}(76 \%)$ and $27 \mathrm{~dB}$. We confirmed that the prototype antennas satisfied the requirements of an aperture efficiency of $70 \%$ and XPD of $25 \mathrm{~dB}$, regardless of the aperture diameter and received polarization.

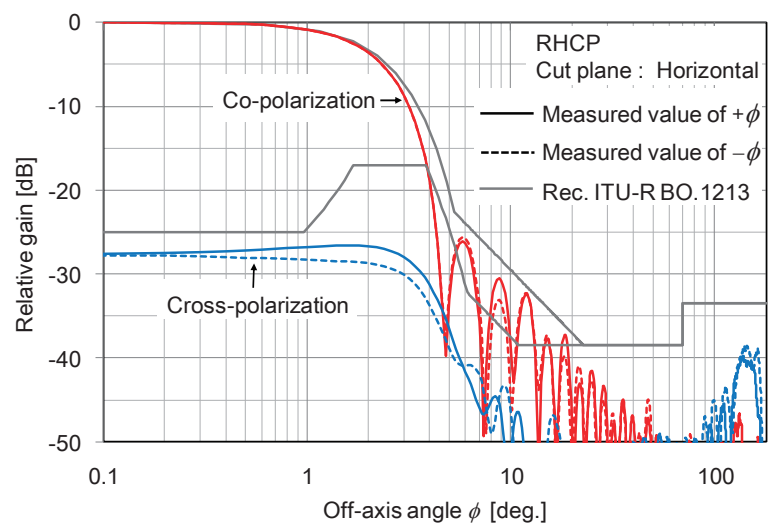

Table 2. Measured results of antenna gain.

\begin{tabular}{|c|c|c|c|c|}
\hline \multirow{2}{*}{$\begin{array}{c}\text { Frequency } \\
{[\mathrm{GHz}]}\end{array}$} & \multicolumn{4}{|c|}{ Gain [dBi] (Aperture efficiency [\%]) } \\
\cline { 2 - 5 } & DHiameter: $45 \mathrm{~cm}$ & \multicolumn{2}{c|}{ Diameter: $60 \mathrm{~cm}$} \\
\hline 11.70 & $33.7(76.2)$ & $33.6(74.6)$ & $36.1(76.1)$ & $36.1(76.0)$ \\
\hline 11.85 & $33.8(77.0)$ & $33.7(74.6)$ & $36.3(77.2)$ & $36.3(77.5)$ \\
\hline 12.00 & $33.9(76.9)$ & $33.8(74.4)$ & $36.5(77.6)$ & $36.5(78.7)$ \\
\hline 12.25 & $34.1(77.5)$ & $34.0(75.1)$ & $36.6(77.2)$ & $36.7(79.4)$ \\
\hline 12.50 & $34.3(77.8)$ & $34.2(75.2)$ & $36.8(77.6)$ & $36.9(79.3)$ \\
\hline 12.75 & $34.6(78.9)$ & $34.3(74.5)$ & $36.9(76.5)$ & $37.1(78.9)$ \\
\hline
\end{tabular}

Table 3. Measured results of XPD.

\begin{tabular}{|c|c|c|c|c|}
\hline \multirow{2}{*}{$\begin{array}{c}\text { Frequency } \\
{[\mathrm{GHz}]}\end{array}$} & \multicolumn{4}{|c|}{ XPD [dB] } \\
\cline { 2 - 5 } & \multicolumn{2}{|c|}{ Diameter: $45 \mathrm{~cm}[\mathrm{~dB}]$} & \multicolumn{2}{|c|}{ Diameter: $60 \mathrm{~cm}[\mathrm{~dB}]$} \\
\hline 11.70 & 32.5 & 39.6 & 33.9 & 37.2 \\
\hline 11.85 & 29.5 & 38.4 & 39.5 & 44.2 \\
\hline 12.00 & 27.7 & 31.7 & 49.0 & 33.1 \\
\hline 12.25 & 29.5 & 29.6 & 33.3 & 27.6 \\
\hline 12.50 & 33.5 & 34.1 & 29.7 & 27.7 \\
\hline 12.75 & 26.2 & 31.4 & 28.7 & 29.4 \\
\hline
\end{tabular}

\subsection{Radiation pattern}

The measured radiation patterns and reference patterns of Rec. ITU-R BO.1213 are plotted in Figs. 7 to 10. We selected $12.0 \mathrm{GHz}$ and $12.5 \mathrm{GHz}$ for the measurement frequencies as the centers of the broadcasting satellite service (BS, 11.7-12.2 $\mathrm{GHz}$ ) and the fixed satellite service (CS, 12.2-12.75 GHz) bands. In each figure, the left and right graphs respectively plot the characteristics of the RHCP and LHCP antennas. We confirmed that the prototype antennas satisfied BO.1213 in both co-polarization and cross-polarization.

Fig 7. Measured radiation patterns of $45-\mathrm{cm}$ antenna $(12.0 \mathrm{GHz})$. 

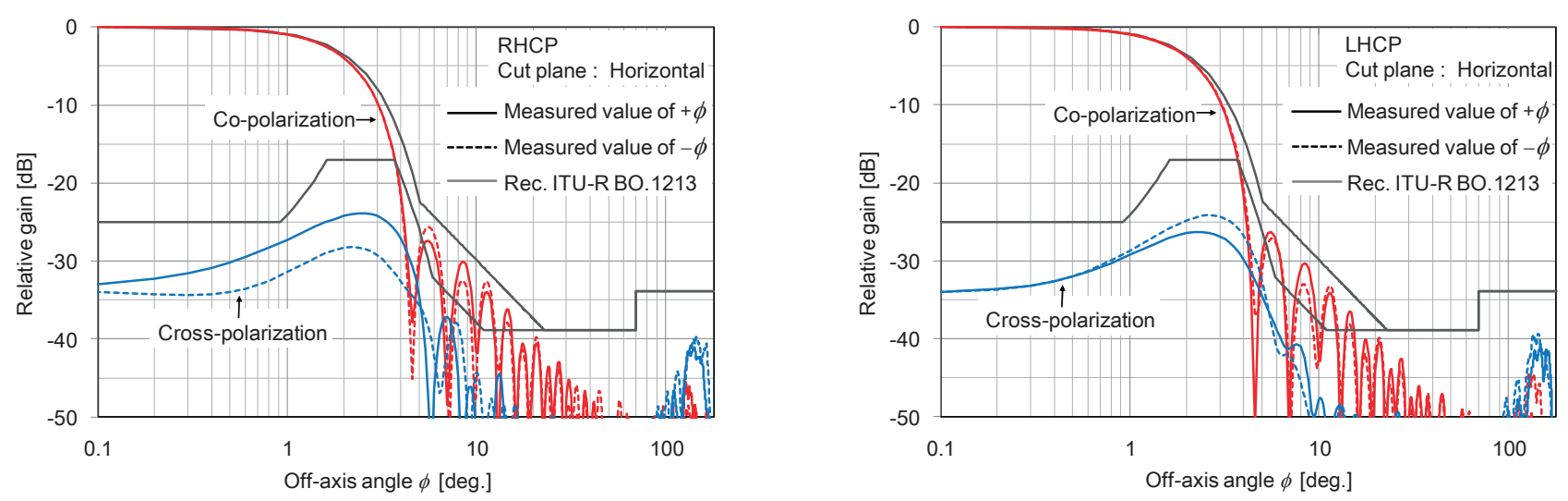

Fig. 8. Measured radiation patterns of $45-\mathrm{cm}$ antenna $(12.5 \mathrm{GHz})$
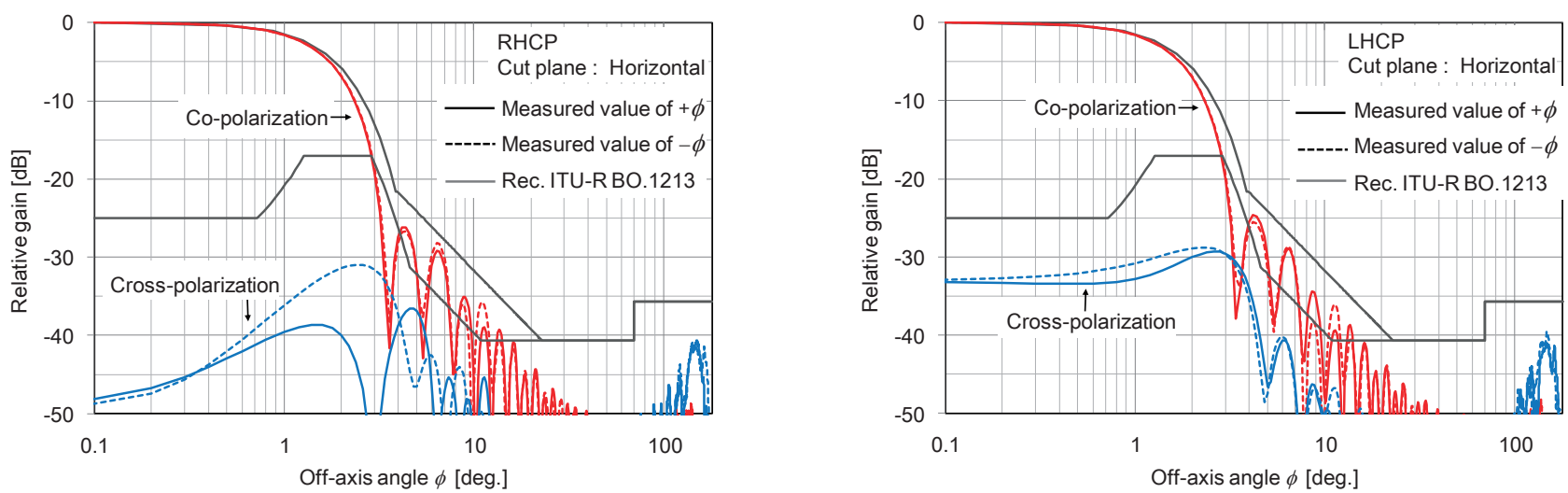

Fig. 9. Measured radiation patterns of $60-\mathrm{cm}$ antenna $(12.0 \mathrm{GHz})$.
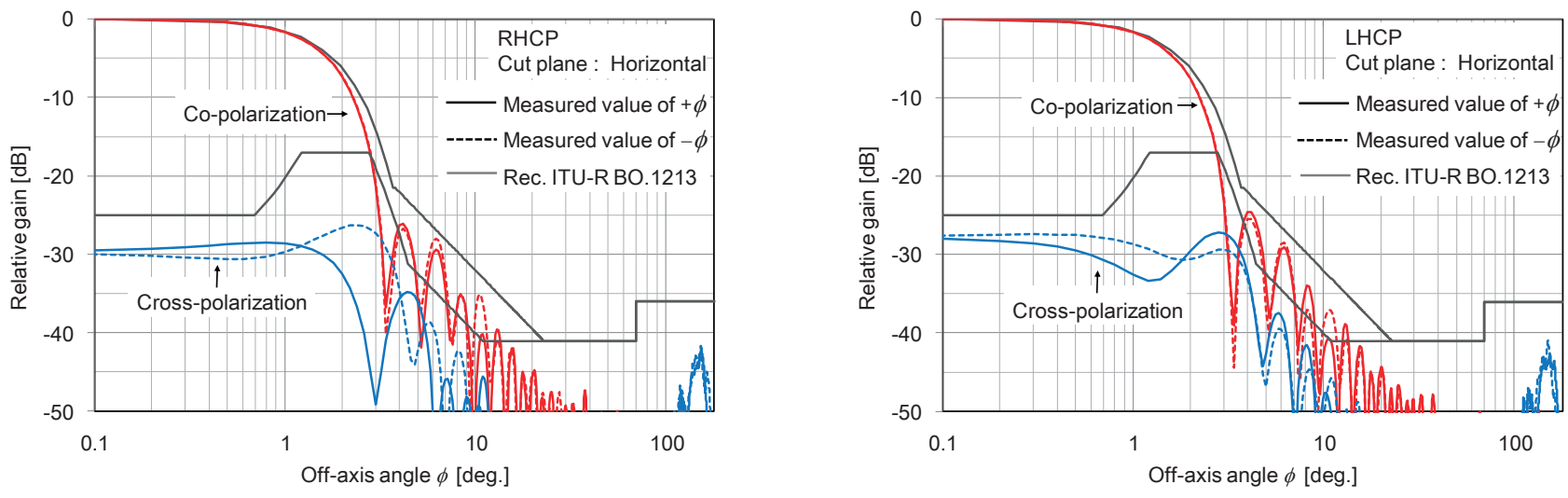

Fig. 10. Measured radiation patterns of $60-\mathrm{cm}$ antenna (12.5 GHz).

\section{Evaluation of Optical Distribution Equipment}

\subsection{Prototype of optical distribution equipment}

We also fabricated and tested optical distribution equipment. Figure 11 shows the prototype equipment, which consists of an optical transmitter $(\mathrm{E} / \mathrm{O})$ and optical receiver $(\mathrm{O} / \mathrm{E})$. Table 4 lists the specifications, which comply with ARIB STD-B63. The prototype was assumed to be for home use, and thus, the transmission frequency was 76 to $3,224 \mathrm{MHz}$, which includes the transmission band of FM radio broadcasting, terrestrial television broadcasting, and satellite broadcasting (IF).

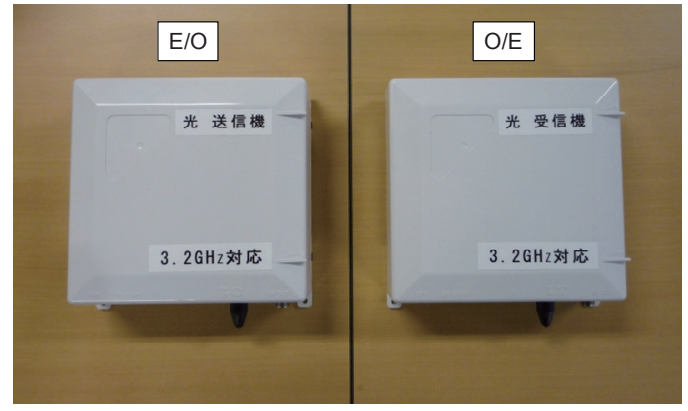

Fig. 11. Prototype of optical distribution equipment. 
Trans. JSASS Aerospace Tech. Japan Vol. 16, No. 2 (2018)

Table 4. Specifications of optical distribution equipment.

\begin{tabular}{|c|c|}
\hline Parameters & Value \\
\hline \hline Transmission frequency & 76 to $3,224 \mathrm{MHz}$ \\
\hline IF input level & $-47.8 \mathrm{dBm}$ \\
\hline Optical wavelength & $1,550 \pm 10 \mathrm{~nm}$ \\
\hline Optical output level & $+6 \mathrm{dBm}$ \\
\hline Optical input level & $-12 \mathrm{dBm}$ to $-6 \mathrm{dBm}$ \\
\hline IF output level & $-23.8 \mathrm{dBm}$ \\
\hline
\end{tabular}

The results of measuring the frequency characteristics are given in Fig. 12. The ratio of the input power of the E/O to the output power of the $\mathrm{O} / \mathrm{E}$ is shown as a gain. The optical input level of the $\mathrm{O} / \mathrm{E}$ was set to $-6 \mathrm{dBm}$, which is the upper limit of the fabricated $\mathrm{O} / \mathrm{E}$. From this figure, we can confirm that the prototype optical distribution equipment had a transmission frequency band of 76 to $3,224 \mathrm{MHz}$, which meets our requirement. In addition, it can be seen that the gain deviation of the satellite broadcasting IF band (1,032 to $3,224 \mathrm{MHz})$ was suppressed to $\pm 1 \mathrm{~dB}$.

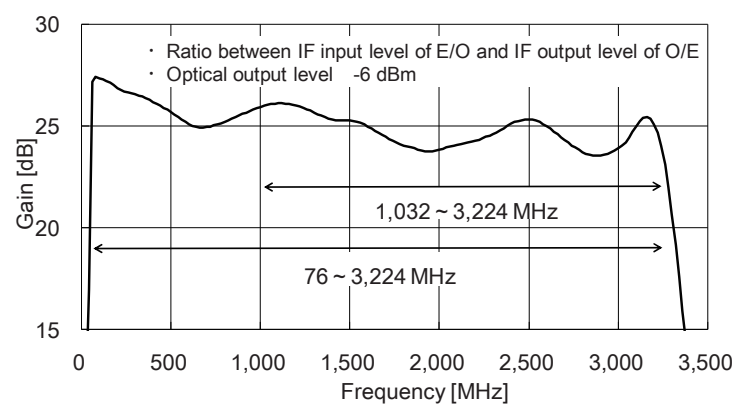

Fig. 12. Frequency characteristics of optical distribution equipment.

\subsection{Evaluation of optical distribution equipment by measuring BER}

The performance of the optical distribution equipment was evaluated by measuring the bit error rate (BER) for ISDB-S3. Figure 13 is a schematic outline of our measurement system to evaluate the optical distribution equipment. Table 5 lists the experimental parameters for ISDB-S3 modulator and demodulator. The 50 modulated waves were input to the optical equipment to simulate the transmission of the RHCPand LHCP-IF signals. Table 6 lists the channel numbers and center frequencies of satellite broadcasting in Japan. We used frequency converters to evaluate the performance in the LHCP-IF band because our prototype modulator and demodulator for ISDB-S3 only conformed to the RHCP-IF band at the moment.

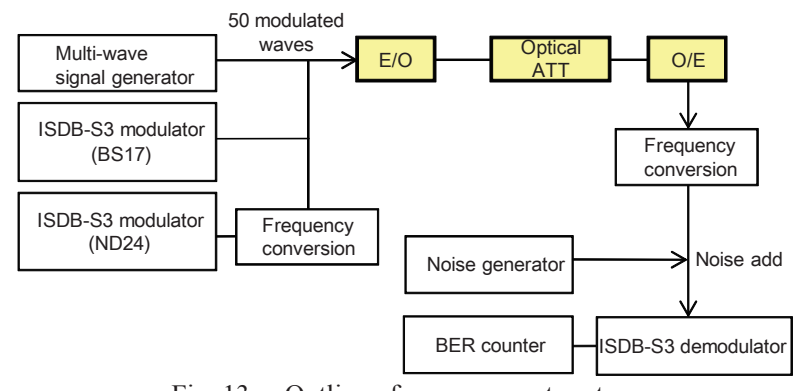

Fig. 13. Outline of measurement system.
Table 5. Main transmission parameters for experiment.

\begin{tabular}{|c|c|c|}
\hline \multicolumn{2}{|c|}{ Modulation (code rate) } & 16APSK (7/9) \\
\hline \multicolumn{2}{|c|}{ Information bit rate } & $99.95 \mathrm{Mbps}$ \\
\hline \multicolumn{2}{|c|}{ Symbol rate } & $33.7561 \mathrm{Mbaud}$ \\
\hline \multicolumn{2}{|c|}{ Roll-off factor } & 0.03 \\
\hline \multirow{2}{*}{ FEC } & Inner code & LDPC (code length 44,880$)$ \\
\cline { 2 - 3 } & Outer code & Shortened code of BCH \\
\hline
\end{tabular}

Table 6. Channel allocation of BS/CS-IF (center frequency).

\begin{tabular}{|c|c|c|c|c|c|}
\hline Band & Channel & $\begin{array}{c}\text { Frequency } \\
{[\mathrm{MHz}]}\end{array}$ & Band & Channel & $\begin{array}{c}\text { Frequency } \\
{[\mathrm{MHz}]}\end{array}$ \\
\hline \multirow{12}{*}{$\begin{array}{l}\text { BS-IF } \\
\text { RHCP }\end{array}$} & BS 1 & 1049.48 & \multirow{12}{*}{$\begin{array}{l}\text { BS-IF } \\
\text { LHCP }\end{array}$} & BS 2 & 2241.66 \\
\hline & BS 3 & 1087.84 & & BS 4 & 2280.02 \\
\hline & BS 5 & 1126.20 & & BS 6 & 2318.38 \\
\hline & BS 7 & 1164.56 & & BS 8 & 2356.74 \\
\hline & BS 9 & 1202.92 & & BS 10 & 2395.10 \\
\hline & BS 11 & 1241.28 & & BS 12 & 2433.46 \\
\hline & BS 13 & 1279.64 & & BS 14 & 2471.82 \\
\hline & BS 15 & 1318.00 & & BS 16 & 2510.18 \\
\hline & BS 17 & 1356.36 & & BS 18 & 2548.54 \\
\hline & BS 19 & 1394.72 & & BS 20 & 2586.90 \\
\hline & BS 21 & 1433.08 & & BS 22 & 2625.26 \\
\hline & BS 23 & 1471.44 & & BS 24 & 2663.62 \\
\hline \multirow{13}{*}{$\begin{array}{l}\text { CS-IF } \\
\text { RHCP }\end{array}$} & ND 26 & 1550 & \multirow{13}{*}{$\begin{array}{l}\text { CS-IF } \\
\text { LHCP }\end{array}$} & ND 25 & 2726 \\
\hline & ND 2 & 1613 & & ND 1 & 2766 \\
\hline & ND 4 & 1653 & & ND 3 & 2806 \\
\hline & ND 6 & 1693 & & ND 5 & 2846 \\
\hline & ND 8 & 1733 & & ND 7 & 2886 \\
\hline & ND 10 & 1773 & & ND 9 & 2926 \\
\hline & ND 12 & 1813 & & ND 11 & 2966 \\
\hline & ND 14 & 1853 & & ND 13 & 3006 \\
\hline & ND 16 & 1893 & & ND 15 & 3046 \\
\hline & ND 18 & 1933 & & ND 17 & 3086 \\
\hline & ND 20 & 1973 & & ND 19 & 3126 \\
\hline & ND 22 & 2013 & & ND 21 & 3166 \\
\hline & ND 24 & 2053 & & ND 23 & 3206 \\
\hline
\end{tabular}

The BS17 and ND24 channels were selected in this experiment because BS17 is currently used for UHDTV test satellite broadcasting, and ND24 is nearest to the center frequency of the satellite broadcasting IF. We measured the BER for 16APSK (7/9). ${ }^{5,6)}$ Here, the optical input level of the $\mathrm{O} / \mathrm{E}$ was set to $-6 \mathrm{dBm}$.

Figures 14 and 15 show the signal waveform and constellation of the $\mathrm{O} / \mathrm{E}$ output. Figure 16 plots the $\mathrm{C} / \mathrm{N}$ versus BER characteristics. Table 7 lists the required carrier-to-noise ratio $(\mathrm{C} / \mathrm{N})$ obtained from our $\mathrm{BER}$ measurement of Fig. 16. The measurements were observed until the BER reached $10^{-8}$ when $10^{10}$ bits were transmitted. The required $\mathrm{C} / \mathrm{N}(\mathrm{P} 4)$ was defined as the $\mathrm{C} / \mathrm{N}$ at which the BER was $1 \times 10^{-11}$ and the $\mathrm{C} / \mathrm{N}$ value was derived from an extrapolation of three measurement points (P1, P2, P3). By setting $\mathrm{C} / \mathrm{N}$ and $\mathrm{BER}$ at each point as $\mathrm{P} 1(\mathrm{CN} 1, \mathrm{BER} 1)$, $\mathrm{P} 2(\mathrm{CN} 2, \mathrm{BER} 2), \mathrm{P} 3(\mathrm{CN} 3, \mathrm{BER} 3)$, the required $\mathrm{C} / \mathrm{N}(\mathrm{CN} 4)$ was obtained from Eq. (1). ${ }^{6}$

Required $C / N=C N 4$

$$
=2 \cdot \frac{\log \left(10^{-11}\right)-\log (B E R 3)}{\frac{\log (B E R 2)-\log (B E R 1)}{C N 2-C N 1}+\frac{\log (B E R 3)-\log (B E R 2)}{C N 3-C N 2}}+C N 3
$$




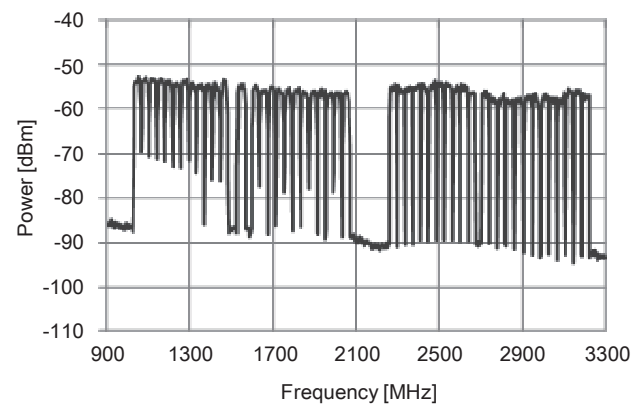

Fig. 14. Output-signal waveform of $\mathrm{O} / \mathrm{E}$ (50 modulated waves).

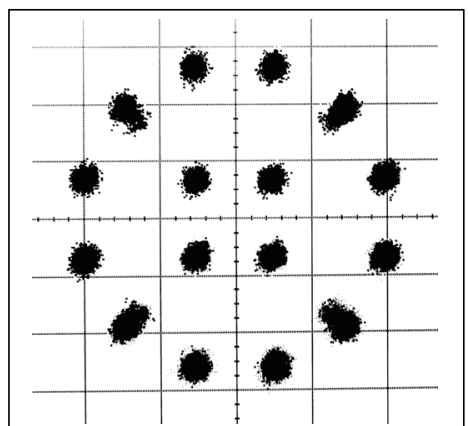

Fig. 15. Output-signal constellation of O/E (16APSK (7/9)).

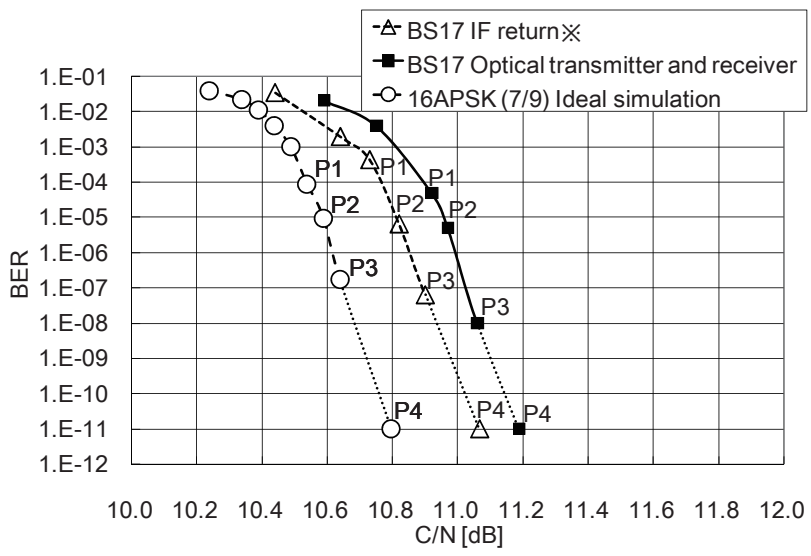

(a) Measured results in BS17

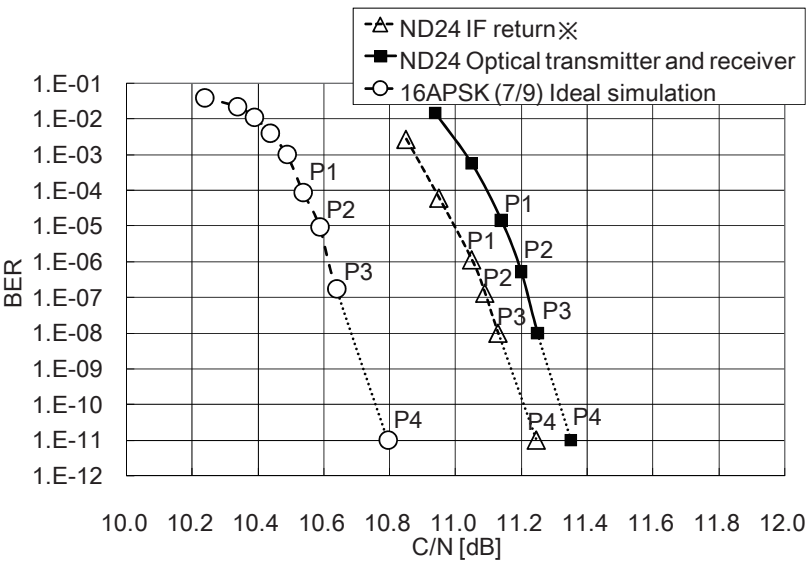

(b) Measured results in ND24

Fig. 16. Measured results of $\mathrm{C} / \mathrm{N}$ vs. BER. ※Measurement result when excluding E/O, optical ATT, and O/E in Fig. 13.
Table 7 indicates that the degradation of the required $\mathrm{C} / \mathrm{N}$ was $0.1 \mathrm{~dB}$ for the fabricated optical distribution equipment.

Table 7. BER measurement results.

\begin{tabular}{|c|c|c|c|c|}
\hline Channel & \multicolumn{2}{|c|}{ BS 17} & \multicolumn{2}{c|}{ ND 24 } \\
\hline $\begin{array}{c}\text { Measurement } \\
\text { condition }\end{array}$ & IF return $\%$ & $\begin{array}{c}\text { Optical } \\
\text { transmitter } \\
\text { and receiver }\end{array}$ & IF return $\%$ & $\begin{array}{c}\text { Optical } \\
\text { transmitter } \\
\text { and receiver }\end{array}$ \\
\hline \hline Required C/N & $11.07 \mathrm{~dB}$ & $11.19 \mathrm{~dB}$ & $11.25 \mathrm{~dB}$ & $11.35 \mathrm{~dB}$ \\
\hline $\begin{array}{c}\text { Degradation of } \\
\text { required C/N }\end{array}$ & & $0.12 \mathrm{~dB}$ & & $0.10 \mathrm{~dB}$ \\
\hline
\end{tabular}

※Measurement result when excluding E/O, optical ATT, and O/E in Fig. 13.

\section{Conclusion}

We fabricated a dual-polarization receiving antenna and optical distribution equipment for 12-GHz-band satellite broadcasting, in accordance with the specifications of ARIB STD-B63. The measurement results for the receiving antenna showed that the aperture efficiency was more than $74 \%$ and that the XPD was more than $26 \mathrm{~dB}$ throughout the $12-\mathrm{GHz}$ band. The radiation patterns were in accordance with the reference pattern of Rec. ITU-R BO.1213. We also confirmed that the fabricated optical distribution equipment was able to deliver 50 modulated IF signals simultaneously with $\mathrm{C} / \mathrm{N}$ degradation of $0.1 \mathrm{~dB}$.

\section{Acknowledgments}

The authors would like to thank the Japan Cable Television Engineering Association (JCTEA) for providing the measurement equipment.

\section{References}

1) Recommendation ITU-R BT.2020-2: Parameter Values for Ultra-high Definition Television Systems for Production and International Programme Exchange, 2015.

2) Association of Radio Industries and Businesses: Receiver for Advanced Wide Band Digital Satellite Broadcasting, ARIB STD-B63 1.6-E1, 2016.

3) Recommendation ITU-R BO.1213-1: Reference Receiving Earth Station Antenna Pattern for the Broadcasting-satellite Service in the 11.7-12.75 GHz Band, 2011.

4) Japan Electronics and Information Technology Industries Association: Methods of Measurement on Receiving Antennas for SHF Satellite Broadcast Transmissions (Electrical Characteristics), JEITA CP-5104C, 2011 (in Japanese).

5) Recommendation ITU-R BO.2098-0: Transmission System for UHDTV Satellite Broadcasting, 2016.

6) Association of Radio Industries and Businesses: Transmission System for Advanced Wide Band Digital Satellite Broadcasting, ARIB STD-B44 2.0-E1, 2014. 